\title{
Reliability of Triggered EMG for Prediction of Safety during Pedicle Screw Placement in Adolescent Idiopathic Scoliosis Surgery
}

\author{
Woo-Kie Min'1, Hyun-Joo Lee ${ }^{1}$, Won-Ju Jeong ${ }^{1}$, Chang-Wug Oh¹, Jae-Sung Bae², \\ Hwan-Seong Cho', In-Ho Jeon', Chang-Hyun Cho', Byung-Chul Park ${ }^{1}$ \\ 'Department of Orthopaedic Surgery, Kyungpook National University Hospital, \\ Kyungpook National University School of Medicine, Daegu, Korea \\ ${ }^{2}$ Department of Physiology, Kyungpook National University School of Medicine, Daegu, Korea
}

Study Design: We performed a prospective study to evaluate the reliability of using triggered electromyography (EMG) for predicting pedicle wall breakthrough during the placement of pedicle screw in adolescent idiopathic scoliosis surgery.

Purpose: We wanted to correlate pedicle wall breakthrough with the triggered EMG threshold of stimulation and the postoperative computed tomography (CT) findings.

Overview of the Literature: Pedicle wall breakthrough has been reported to be difficult to evaluate by radiographs. Triggered EMG had been found to be a more sensitive test to detect this breakthrough.

Methods: Seven patients who underwent the insertion of 103 pedicle screws were evaluated. The triggered EMG activity was recorded from several muscles depending on the level of screw placement. The postoperative CT scans were read by a spine surgeon who was a senior fellow in orthopedics, and a musculoskeletal radiologist.

Results: The mean age at surgery was 12.6 years (range, 11 to 17 years). The preoperative mean Cobb angle was $54.7^{\circ}$ (range, 45 to $65^{\circ}$ ). There were 80 thoracic screws and 23 lumbar screws. All the screws had stimulation thresholds of $\geq 6 \mathrm{~mA}$, except 3 screws with the stimulation threshold of $<6 \mathrm{~mA}$. Ten screws $(9.7 \%)$ showed violation of the pedicle wall on the postoperative CT scans. Five screws penetrated medially and another five penetrated laterally. No postoperative neurologic complications were noted in any of the seven patients.

Conclusions: Measuring the stimulation threshold of triggered EMG helps to assess the pedicle screw placement. Pedicle screws that had stimulation threshold of $\geq 6 \mathrm{~mA}$ were safe, with $90.3 \%$ reliability, as was assessed on the postoperative CT scans.

Key Words: Adolescent idiopathic scoliosis, Pedicle screw, Triggered electromyography

\section{Introduction}

Correcting deformity using pedicle screw fixation in patients with adolescent idiopathic scoliosis is currently widely accepted. Although the use of thoracic pedicle screws may result in better deformity correction and fixation, the safe placement of these screws is considered technically challenging because of the small size of the thoracic pedicle and the potential risk to the great vessels, spinal

Received Nov 9, 2009; 1st Revised May 12, 2010; 2nd Revised Sep 13, 2010; Accepted Sep 15, 2010

Corresponding author: Woo-Kie Min, MD, PhD

Department of Orthopedic Surgery, Kyungpook National University School of Medicine,

50 Samdeok-dong 2-ga, Jung-gu, Daegu 700-712, Korea

Tel: +82-53-420-5638, Fax: +82-53-422-6605, E-mail: wkmin@knu.ac.kr 
cord and spinal nerve roots [1-3]. The rates of penetrating the pedicle cortex, depending on the employed techniques, have ranged from $15.9 \%$ to $54.7 \%$ in laboratory studies with cadavers $[4,5]$. Clinically, bony landmarks and intraoperative $\mathrm{C}$-arm X-rays are commonly used to determine the correct placement, yet these methods are frequently inaccurate $[1,4,6,7]$. Screw violation of the thoracic pedicle cortex has been reported at a rate of over $8 \%$ [8]. Incorrect placement rates as high as $42 \%$ have been reported with manual screw insertion. Although several methods are used for increasing the accuracy of pedicle screw placement, fluoroscopic guidance has been shown to be insufficient to reliably predict the exit of screws $[2,7,9]$. Computed tomographic (CT) scans are significantly more sensitive and accurate for evaluating pedicle screw placement than are plain radiograph [7], but performing CT scans is feasible only after surgery in most medical centers. Computer-aided stereotaxic guidance systems have been used in the operating room to assist in the correct placement of the pedicle screws, and this may help lower the pedicle wall perforation rate [10], but these systems are costly and they require much space for the equipment and also more time, which make the general application of this technique difficult. After the use of electrical stimulation of pedicle screws for the evaluation of their placement was developed by Calancie et al. [11], several recent animal studies have investigated the evoked electromyography (EMG) responses to assess pedicle screws that were placed in levels above the lumbar spine. Danesh-Clough et al. [12] used an ovine model for examining lower thoracic pedicle screws. They recorded the evoked potential from the transversus abdominis, intercostal and iliopsoas muscles. The study concluded that an evoked EMG threshold of $<10 \mathrm{~V}$ was an effective tool for detecting pedicle screw misplacement. The sensitivity and specificity were $94 \%$ and $90 \%$, respectively. Lewis et al. [13] demonstrated the reliability of triggered EMG stimulation for confirming the thoracic pedicle screw placement in a porcine model. They chose the intercostals muscles. However, no absolute threshold or range of threshold values was correlated with medially misdirected screws. So, the rectus abdominis muscles were alternately chosen as a recording site because of their innervation from the T6-T12 thoracic nerve roots. Raynor et al. [14] recently reported that triggered EMG thresholds of $<6.0 \mathrm{~mA}$, coupled with the values of a $60-65 \%$ decrease from the mean of all the other thresholds during thoracic pedicle screw placement, should alert the surgeon to suspect a breach of the medial pedicle wall. There are only a few studies that have evaluated the reliability of intraoperative triggered EMG for predicting safe pedicle screw placement in adolescent idiopathic scoliosis patients. We evaluated the threshold of intraoperative triggered EMG and the accuracy of pedicle screw placement using postoperative CT scanning for assessing the position of pedicle screws.

\section{Materials and Methods}

One hundred-three pedicle screws were inserted and successfully examined using intraoperative triggered EMG in 7 adolescent idiopathic scoliosis patients who were undergoing deformity correction surgery from November 2007 to February 2009 (Tables 1 and 2). The mean body mass index of the patients was 21.2 (range, 14.6 to 27.4). All the screws were placed by a single surgeon (WK Min). The diameter of all the pedicle screws was $5.5 \mathrm{~mm}$ and the length of the pedicle screw was from 35 to $40 \mathrm{~mm}$. The thoracolumbar vertebral levels that were instrumented included T5 (14 screws), T6 (8 screws), T7 (10 screws), T8 (10 screws), T9 (9 screws), T10 (9 screws), T11 (9 screws), T12 (11 screws), L1 (12 screws), L2 (5 screws) and L3 (6 screws) (Table 1). All the pedicle screws were inserted using a free hand technique. A special probe was advanced into the vertebral body through the pedicles. A sounding device was used to palpate five bony borders (the floor and the proximal, distal, medial and lateral borders). Using a tapper, the pedicle hole was tapped and the tapped pedicle hole was palpated again. A proper sized pedicle screw was placed into the hole. The triggered EMG activities from stimulation of the screws at T5-T12 were recorded from the abdominal muscles. The electrodes for recording the

Table 1. Distribution of screws

\begin{tabular}{ccccccccccccc}
\hline \hline & \multicolumn{10}{c}{ Screw levels } & L \\
\cline { 2 - 9 } & T5 & T6 & T7 & T8 & T9 & T10 & T11 & T12 & L1 & L2 & L3 & Total \\
\hline No. of screws & 14 & 8 & 10 & 10 & 9 & 9 & 9 & 11 & 12 & 5 & 6 & 103 \\
\hline
\end{tabular}


Table 2. Screw-evoked threshold by patients

\begin{tabular}{|c|c|c|c|c|c|c|c|c|c|c|c|}
\hline \multirow[b]{2}{*}{ Patient } & \multicolumn{11}{|c|}{ Evoked EMG thresholds in mA and screw levels (left/right) } \\
\hline & $\mathrm{T} 5$ & T6 & $\mathrm{T} 7$ & $\mathrm{~T} 8$ & T9 & $\mathrm{T} 10$ & T11 & $\mathrm{T} 12$ & L1 & L2 & L3 \\
\hline 1 & $7 / 6$ & & $8 /$ & 17 & $7 /$ & 18 & $8 /$ & $9 /$ & $9 / 9$ & $10 /$ & $9^{\mathrm{a})}(\mathrm{M}) / 9$ \\
\hline 2 & $7 / 7$ & $8 / 7$ & $7 /$ & $7 / 8$ & 17 & $9^{\mathrm{a})}(\mathrm{L}) /$ & 17 & $10 /$ & $11 / 9$ & $10 / 10$ & $12 / 9$ \\
\hline 3 & $7 / 7$ & & $7 / 7$ & $8 /$ & $/ 6$ & 11/ & $7 / 7$ & $7 / 6$ & & & \\
\hline 4 & $8^{\mathrm{a}}(\mathrm{M}) / 8^{\mathrm{a}}(\mathrm{L})$ & 8/ & $8 / 8^{\mathrm{a}}(\mathrm{M})$ & $8 /$ & $9^{\mathrm{a})}(\mathrm{L}) / 9$ & $8 /$ & $8 / 9$ & 9/ & $8 / 9$ & $9 / 11$ & $11 / 14$ \\
\hline 5 & $7 / 7$ & $7 / 6^{\mathrm{a})}(\mathrm{M})$ & 7/ & $8 / 8$ & $7 /$ & $9 / 7$ & $8 /$ & $10 / 8$ & $9 / 9$ & & \\
\hline 6 & $7 / 7^{\mathrm{a}}(\mathrm{L})$ & $8 / 7$ & $9 / 8$ & $7 /$ & $8 / 7$ & $8 /$ & $8 /$ & $9 / 9$ & $10 / 9$ & & \\
\hline 7 & $8 / 6$ & $8 /$ & $10 /$ & $11 / 6$ & $10 /$ & $10^{\mathrm{a})}(\mathrm{L}) / 6^{\mathrm{a}}(\mathrm{M})$ & $8 /$ & $6 / 7$ & $9 / 8$ & 8 & \\
\hline
\end{tabular}

EMG: Electromyography, M: Medial penetration, L: Lateral penetration

${ }^{a}$ Screw shown to have violated vertebral cortex on postoperative computed tomography. None of the screws caused any clinical complication

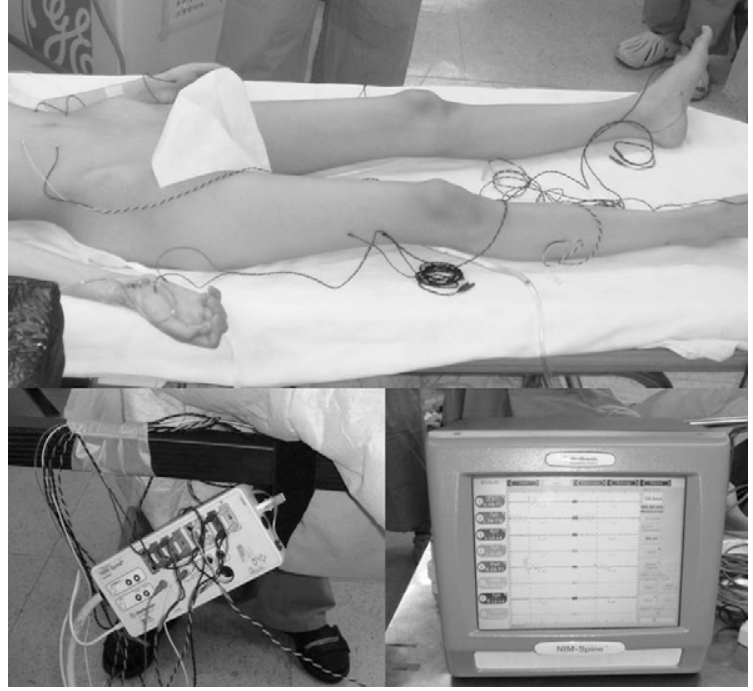

Fig. 1. Placement of the electrodes used to record the electromyography activity triggered through stimulation of the pedicle screws.

abdominal musculature activity from thoracic screw stimulation from T5 to T12 were placed at two points along the nipple line vertically, that equally divided the distance horizontally between the lower margin of the tenth rib and the iliac ridge (Fig. 1). This montage for recording the EMG activity related to lower thoracic nerve root stimulation is considered adequate because all the abdominal muscles receive innervations from all the lower thoracic nerve roots, and these innervations overlap each other. Paired electrodes were used for all the muscle groups in order to increase the specificity. The triggered EMG activities from stimulation of the screws at L1, L2 and L3 were recorded from the internal oblique, adductor longus and vastus lateralis muscles. The intraoperative EMG monitoring system we used was a commercially available NIM Spine System (Medtron- ic Sofamor Danek, Memphis, TN, USA). General anesthesia was done by a special spine anesthesiologist who followed the recommended anesthesia protocol for motor evoked potential (MEP) monitoring. Pre-medication with midazolam was considered not to affect the MEPs. Up to $50 \%$ nitrous oxide was used. Since the amplitudes of the MEPs are easily abolished with using volatile anesthetics, these amplitudes of the MEPs can be obtained with using less than a 0.5 minimum alveolar concentration and using a multi-pulse stimulus. Propofol was infused at 10-12 $\mathrm{mg} / \mathrm{kg} / \mathrm{hr}$ during the first 1 hour and at $6-8 \mathrm{mg} / \mathrm{kg} / \mathrm{hr}$ for the remaining time. Narcotics have minimal affect on MEPs if the narcotics are infused. Bolus doses of narcotics can cause prolonged amplitude reductions. When they were used, the doses were as follows; fentanyl: $1-3 \mathrm{mcg} / \mathrm{kg} / \mathrm{hr}$, alfentanil: $10-20 \mathrm{mcg} / \mathrm{kg} / \mathrm{hr}$ and sufentanil: $0.1-0.3 \mathrm{mcg} / \mathrm{kg} / \mathrm{hr}$. Neuromuscular blocker was not used except for intubation. If needed, short acting succinylcholine or mivacurium was used.

The current intensity was slowly increased from zero until either the EMG activity was visually identified from the monitored muscle. The surgical field was kept dry while performing stimulation.

All the patients underwent postoperative CT scans at the levels of the instrumented thoracolumbar spine. The postoperative CT scans were reviewed by the operator and a senior spine fellow in orthopedics, and both were 'blind' to the EMG threshold results, to assess the screws' locations. The cases with conflicting results were reviewed as a group by using image contrast enhancement until an agreement between the reviewers emerged. The evoked EMG thresholds for all the screws that were interpreted as exiting the pedicle cortex were analyzed. CT scans were used as a gold 
Table 3. Number of violating screws

\begin{tabular}{lcc}
\hline \hline & Medial cortex breached & Lateral cortex breached \\
\hline Threshold $\geq 6 \mathrm{~mA}$ & 5 & 5 \\
\hline
\end{tabular}

(A)

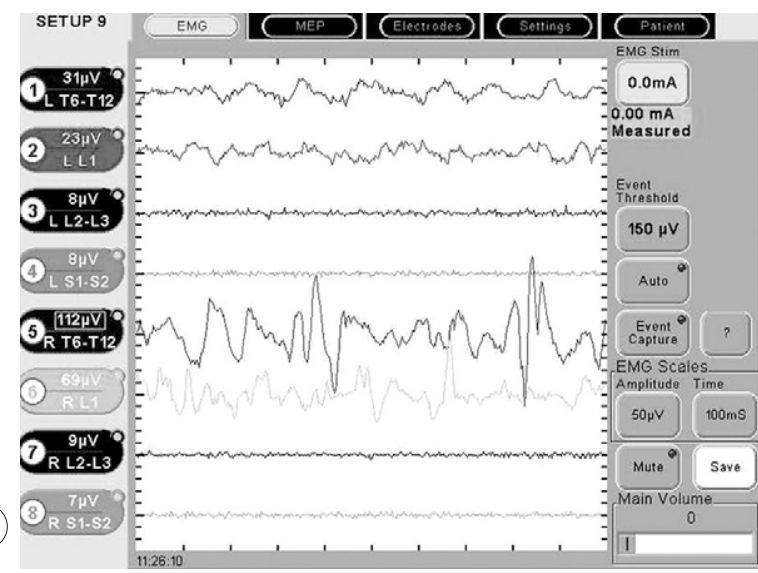

(B)

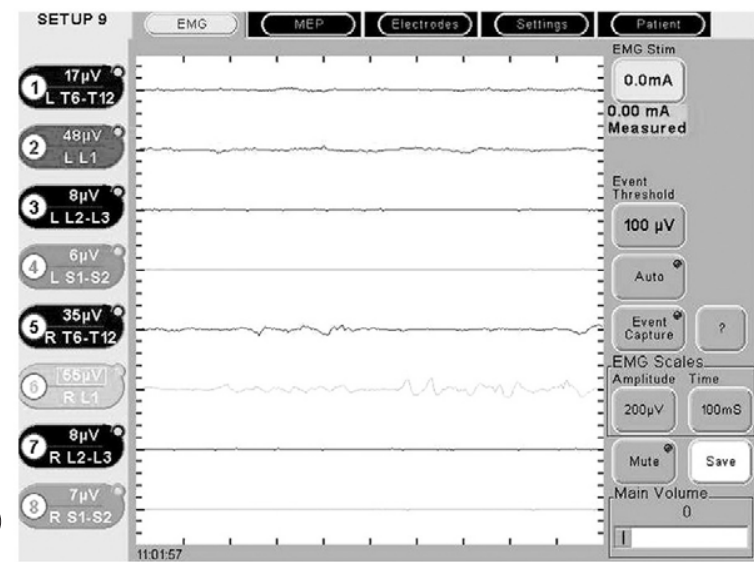

Fig. 2. Note the abnormal alarm findings when a right T6 pedicle screw was inserted (A). After repositioning the screw in the pedicle, the findings of electromyography were normal (B).

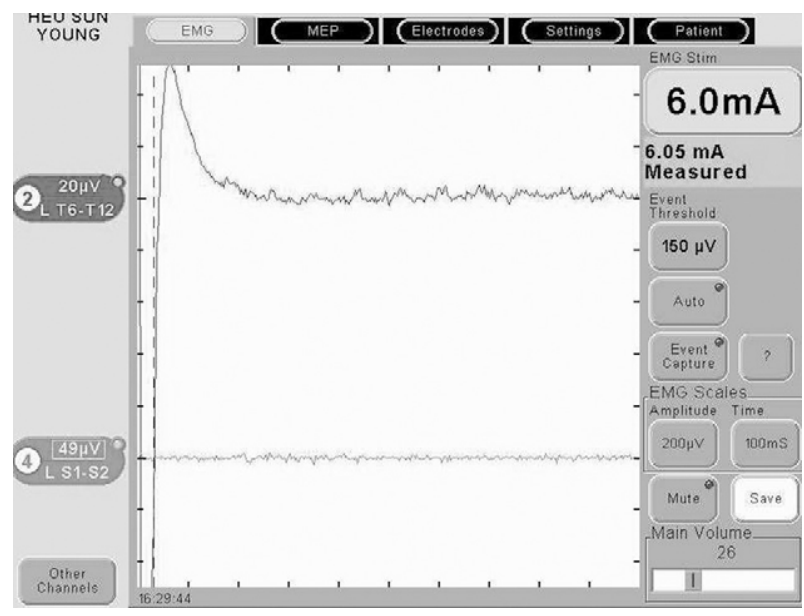

Fig. 3. Note the threshold of electromyography activity triggered by stimulation of pedicle screws is $6 \mathrm{~mA}$.

standard for the decision making of pedicle wall violation. Some screws showed a breached pedicle wall even with their EMG thresholds of $\geq 6 \mathrm{~mA}$ (Table 3). The positive and negative predictive values were calculated using standard statistical equations.

\section{Results}

The mean age of the patients was 12.6 years (range, 11 to 17 years). The preoperative mean Cobb angle was $54.7^{\circ}$ (range, 45 to $65^{\circ}$ ). Among 103 screws, 80 were thoracic screws and 23 were lumbar screws. The triggered EMG activity was successfully recorded from the corresponding muscle groups at every level of pedicle screw placement (Figs. 2 and 3). The EMG thresholds with thoracolumbar pedicle screw stimulation ranged from 6 to $14 \mathrm{~mA}$. Intraoperative EMG thresholds of $<6 \mathrm{~mA}$ were shown by 3 screws $(5 \mathrm{~mA})$, which were reinserted, with the resultant final threshold over $6 \mathrm{~mA}$ (8, 6 and $9 \mathrm{~mA}$, respectively). We used these final resultant thresholds for evaluating the results.

The postoperative CT scans showed that the medial pedicle cortex was intact for 98 of 103 screws with stimulation thresholds of $\geq 6 \mathrm{~mA}$, for a negative predictive value of $95.1 \%$. Including penetration of the lateral pedicle cortex, the negative predictive value was $90.3 \%$ (93/103). A total of ten screws (9.7\%) were found to have breached the pedicle cortex on the postoperative $\mathrm{CT}$ scans: three at T5, one each at T6, T7 and T9, three at T10 and one at L3 (Figs. 46). Two of these screws had stimulation thresholds at $6 \mathrm{~mA}$, one at $7 \mathrm{~mA}$, three at $8 \mathrm{~mA}$, three at $9 \mathrm{~mA}$ and one at 10 $\mathrm{mA}$ (Table 4). Among those, five screws had violated the medial pedicle wall, which were one at T5 $(8 \mathrm{~mA})$, one at T6 $(6 \mathrm{~mA})$, one at T7 $(8 \mathrm{~mA})$, one at T10 $(6 \mathrm{~mA})$ and one at L3 $(9 \mathrm{~mA})$. Table 5 shows the distribution of the screws interpreted according to the intra- and final resultant stimulation thresholds and the penetration of the medial cortex. Palpation during pedicle preparation did not detect perforation by any of these 5 screws, and they were interpreted as acceptable on the intraoperative fluoroscopy. The postoperative $\mathrm{CT}$ scan of a screw that was interpreted as exiting the pedicle medially at $\mathrm{T} 7$ in patient 4 showed a stimulation 
threshold of $8 \mathrm{~mA}$ (Fig. 6). No change was identified in the concurrently monitored upper and lower extremity MEP immediately after the deformity correction procedure (rod derotation) in any of these patients. There were no postoperative neurologic deficits or neurologic pain in any of the patients in this study. There were no complications related to placement of the EMG electrodes. No early or late complications attributable to the thoracolumbar pedicle screw insertion were noted.

\section{Discussion}

Spinal deformity correction using pedicle screw instru-

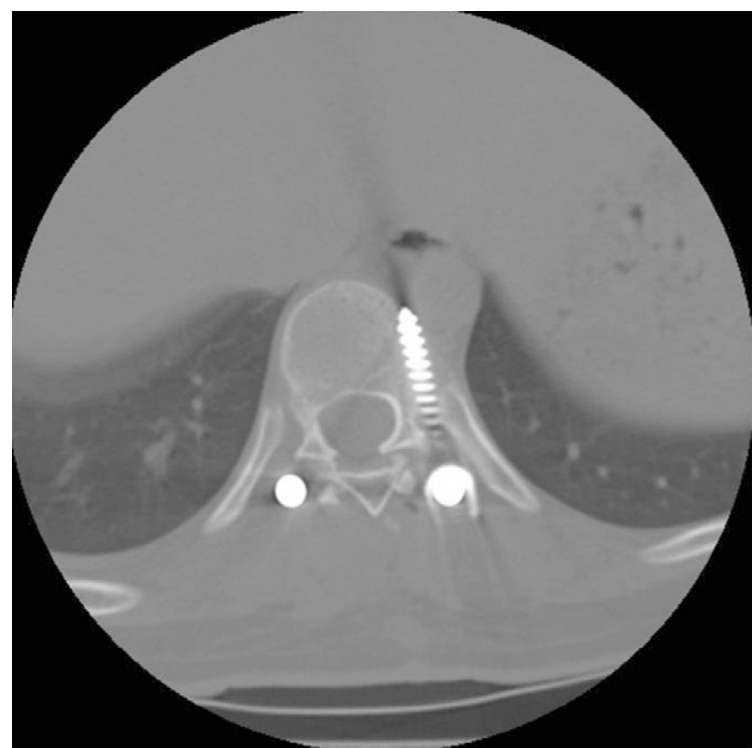

Fig. 4. Laterally placed screws at $\mathrm{T} 10$ in patient 2 . The screw on the left side breached the vertebral body on the lateral side. The evoked electromyography threshold for this screw was $11 \mathrm{~mA}$. mentation is well recognized as an effective and powerful technique. However, the reported experience with pedicle screw placement in the thoracic vertebrae remains relatively limited, and especially in adolescent idiopathic scoliosis. Because of the young age and the smaller size of thoracic vertebral pedicles, the risk of cortical breakout is probably greater than that for the lumbar vertebrae. Serious effects of errors in screw placement can occur because of the proximity of the neurovascular structures, and especially the spinal cord. For these reasons, a reliable method of assessing the position of screws is critically important when applying tho-

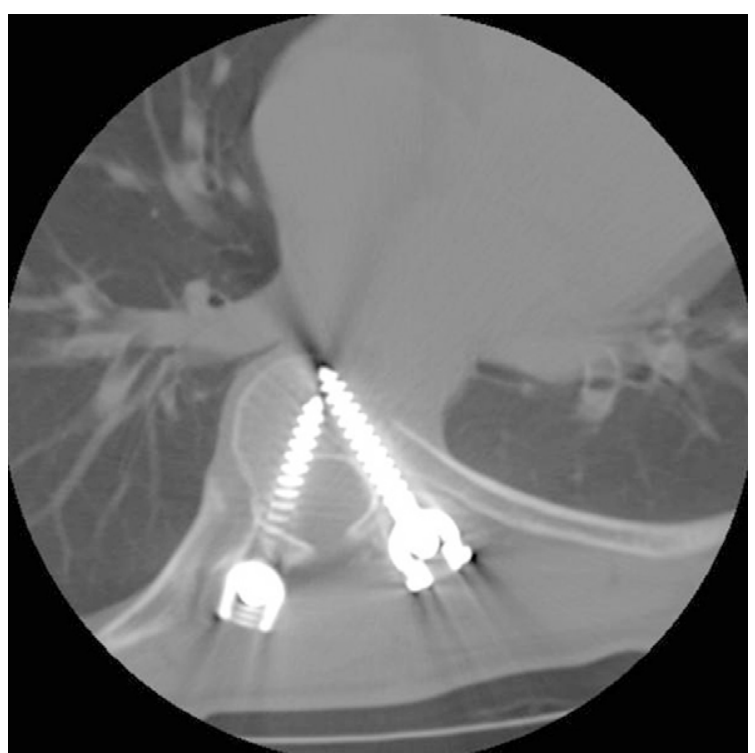

Fig. 6. Medially placed screws at $\mathrm{T} 7$ in patient 4 . The screw on the right side breached the vertebral body on the medial side. Yet the intraoperative electromyography threshold for this screw was $8 \mathrm{~mA}$. The right screw was interpreted to be within the bone. The threshold for this screw was $8 \mathrm{~mA}$.

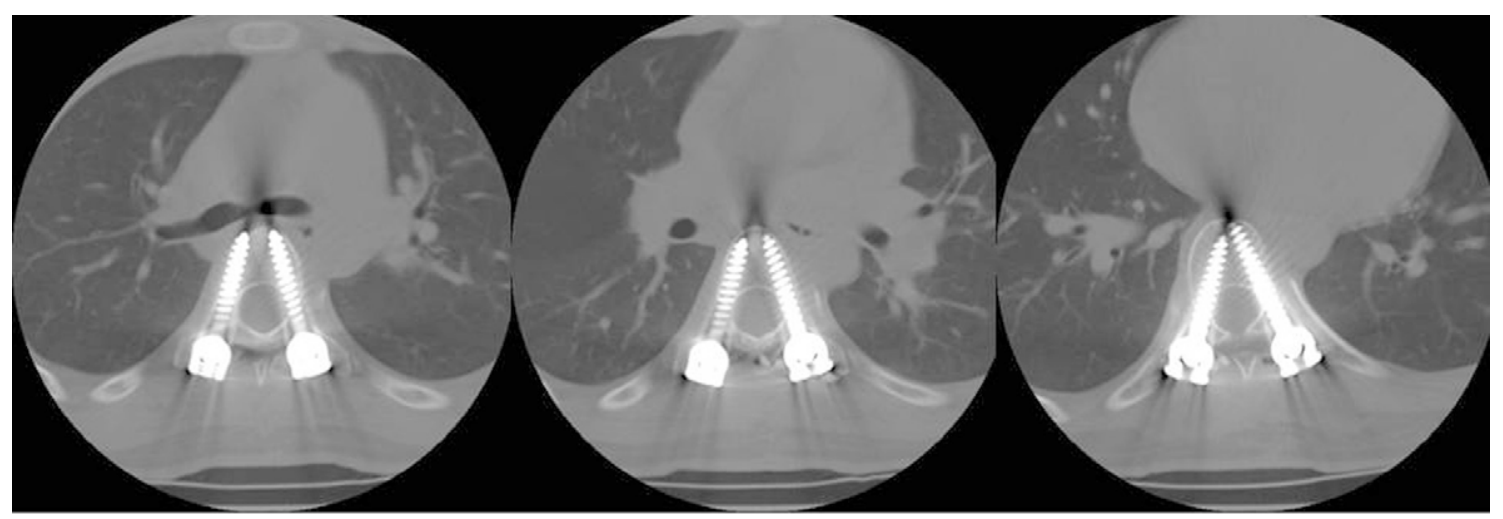

Fig. 5. No cortical violation can be identified for both the left and right screws at $\mathrm{T} 5$, $\mathrm{T} 6$ and $\mathrm{T} 8$ in patient 2 . The evoked electromyography threshold for these screws was $7 \mathrm{~mA}, 8 \mathrm{~mA}, 7 \mathrm{~mA}$ (left) and $7 \mathrm{~mA}, 7 \mathrm{~mA}, 8 \mathrm{~mA}$ (right) at T5, T6 and T8, respectively. 
Table 4. Locations and associated evoked electromyography (EMG) thresholds of the ten screws interpreted as violating vertebral cortices

\begin{tabular}{lcc}
\hline \hline Screw location & EMG threshold (mA) & Associated complication \\
\hline T5 left (1)/right (2) & $8 / 8,7$ & None \\
T6 right & 6 & None \\
T7 right & 8 & None \\
T9 left & 9 & None \\
T10 left (2)/right (1) & $9,10 / 6$ & None \\
L3 left & 9 & None \\
\hline
\end{tabular}

Table 5. Distribution of the screws interpreted as intra- and final resultant stimulation threshold and medial cortex

\begin{tabular}{lccc}
\hline \hline & Violation of medial pedicle cortex & Non-violation of medial pedicle cortex & PPV $=$ N/A \\
Threshhold $<6 \mathrm{~mm}$ & 0 & 0 & NPV $=95.1 \%$ \\
Threshhold $\geq 6 \mathrm{~mm}$ & 5 & 98 & Specificity $=100 \%$ \\
\end{tabular}

PPV: positive predictive value, N/A: not applicable, NPV: negative predictive value.

racic pedicle screws.

The triggered EMG from screw stimulation provides information regarding the physiologic effect of screw placement. It estimates the integrity of the vertebral cortex by measuring the intensity of the electrical energy needed to activate the adjacent nerve roots. The stimulus intensity required to activate the nerve root is directly related to the electrical impedance to passage of current from the screw to the nerve root, which is provided by the intervening structures and most prominently by an intact medial bony cortex of the pedicle [15]. Pedicle screw stimulation has been used for evaluating lumbosacral screws with satisfactory results [16-18]. We are not aware of any reports of similar testing with thoracic screws and especially in young adolescent idiopathic scoliosis patients who probably have a reduced electrical EMG threshold.

The studies of pedicle screw stimulation in lumbosacral vertebrae by Calancie et al. [11] and Clements et al. [17] suggested that thresholds $<10-11 \mathrm{~mA}$ were associated with an increased risk of cortical violation and postoperative neurologic complications. These studies relied on intraoperative probing of the tapped pedicle screw hole for determining the pedicle integrity, but in these studies, not all the examined patients were adolescent idiopathic scoliosis patients. In the current study, postoperative CT scans were used to evaluate the screw position in young adolescent idiopathic scoliosis patients.

In the first case, we found that the range of threshold of the trigger EMG was from $7 \mathrm{~mA}$ to $10 \mathrm{~mA}$ and just one medial cortical violation assessed via the postoperative CT scan. After that, we thought the usual threshold of EMG for adolescent idiopathic scoliosis patients (over $6 \mathrm{~mA}$ ) would be safe for assessing pedicle screw fixation. In a total of seven cases, the appropriate position within the pedicle was confirmed in $90.3 \%$ of the screws with using a triggered EMG thresholds $\geq 6 \mathrm{~mA}$ (90 of 103 screws). Of the five screws showing vertebral medial cortical breakthrough, two had stimulation thresholds at $6 \mathrm{~mA}$. The other three screws were associated with stimulation thresholds of 7,8 and 9 $\mathrm{mA}$, respectively. Although the trajectory of the screw clearly indicates violation of the medial pedicle cortex, it appears that a thin layer of bone may still be present over the screw or the result from plastic deformation of the pedicle. Still, we cannot explain why the screws had the relatively high stimulation threshold. These five screws were all interpreted as intact on intraoperative palpation. This may reflect a higher sensitivity of CT scanning for detecting cortical violation by pedicle screws as compared with that of intraoperative exploration by the surgeon. In Clements et al.'s [17] study, postoperative lumbar radiculopathy was associated with pedicle screw stimulation thresholds of $\leq$ $8.5 \mathrm{~mA}$. None of the five violating screws in our study was associated with negative postoperative clinical consequences.

Similar to the approach taken here, Glassman et al. [18] compared the pedicle stimulation thresholds and the postoperative CT readings in lumbosacral vertebrae. They found that a stimulation threshold of $>15 \mathrm{~mA}$ provided a $98 \%$ confidence that the screw was within the pedicle. The confidence level fell to $87 \%$ for stimulation thresholds between 
10 and $15 \mathrm{~mA}$, and they recommended re-examination of the pedicle in this situation. Our finding that $90.3 \%$ of thoracolumbar screws with thresholds of $\geq 6 \mathrm{~mA}$ were within the pedicle on the postoperative CT scans is quite important because this suggests that adolescent idiopathic scoliosis patients have smaller diameters of their pedicles and a lower threshold of the triggered EMG threshold than was reported by the previous other studies. Further, we thought that a small hole or crack in the pedicle may be difficult to detect on intraoperative exploration and this may have led to decreased stimulation thresholds in some of these screws. Five screws showing stimulation thresholds of $\geq 6 \mathrm{~mA}$ were found to have penetrated the medial vertebral cortex on CT scans (false negatives). We thought that laterally penetrated screws may not affect the threshold of the triggered EMG (Fig. 4).

In patient 4 , the right screw at the $\mathrm{T} 7$ level had a stimulation threshold of $8 \mathrm{~mA}$, but it had violated the pedicle medially, based on its trajectory on the CT scan (Fig. 6). A review of the CT scan suggests that the screw may have caused plastic deformation of the pedicle, leaving a thin layer of bone over the screw. This may have resulted in an intact bony canal on probing and the high impedance that yielded a relatively high stimulation threshold. Regardless of the cause of this false negative value, no clinical consequences to this screw have been detected.

Using $6 \mathrm{~mA}$ as the cutoff point, the test results in this series for thoracolumbar screws yielded a specificity of $100 \%$. If we exclude the laterally penetrated screws, the negative predictive value was $95.1 \%$ (98/103), suggesting that cortical violation is highly unlikely when the test threshold is $\geq 6 \mathrm{~mA}$. The rate of cortical violation was 9.7\% in this series; it is possible that the low positive predictive value partially reflects this low incidence. Again, the surgeon should bear in mind that low triggered EMG thresholds may occur in screws with safe positioning. The final judgment of screw safety must be made based on a combination of information, including thorough canal exploration and intraoperative radiographs, rather than on pedicle screw stimulation thresholds alone.

The results of this limited series show that the evaluation of pedicle screw placement using trigger EMG can be successfully adapted to the thoracolumbar vertebrae of adolescent idiopathic scoliosis patients. We would like to suggest that a triggered EMG threshold of $\geq 6 \mathrm{~mA}$ represented safe screw placement in $90.3 \%$ of the screws in adolescent idiopathic scoliosis patients. The information obtained using triggered EMG from pedicle screw stimulation is rapid and useful intraoperatively, and this may help the surgeon determine if a screw needs to be reevaluated or repositioned to avoid possible postoperative complications. The final decision in terms of screw safety should be based on a combination of the results of the triggered EMG threshold, the intraoperative radiography and palpation of the pedicle, as well as the operator's surgical experience.

\section{Conclusions}

Measuring the stimulation threshold of triggered EMG helps to assess the pedicle screw placement. Pedicle screws that had stimulation threshold of $\geq 6 \mathrm{~mA}$ were safe, with $90.3 \%$ reliability, as was firmly assessed on the postoperative CT scans.

\section{REFERENCES}

1. Krag MH, Weaver DL, Beynnon BD, Haugh LD. Morphometry of the thoracic and lumbar spine related to transpedicular screw placement for surgical spinal fixation. Spine (Phila Pa 1976) 1988;13:27-32.

2. Vaccaro AR, Rizzolo SJ, Allardyce TJ, et al. Placement of pedicle screws in the thoracic spine. Part I: morphometric analysis of the thoracic vertebrae. J Bone Joint Surg Am 1995;77:1193-9.

3. Zindrick MR, Wiltse LL, Doornik A, et al. Analysis of the morphometric characteristics of the thoracic and lumbar pedicles. Spine (Phila Pa 1976) 1987;12:160-6.

4. Cinotti G, Gumina S, Ripani M, Postacchini F. Pedicle instrumentation in the thoracic spine: a morphometric and cadaveric study for placement of screws. Spine (Phila Pa 1976) 1999;24:114-9.

5. Xu R, Ebraheim NA, Ou Y, Yeasting RA. Anatomic considerations of pedicle screw placement in the thoracic spine: Roy-Camille technique versus open-lamina technique. Spine (Phila Pa 1976) 1998;23:1065-8.

6. Faraj AA, Webb JK. Early complications of spinal pedicle screw. Eur Spine J 1997;6:324-6.

7. Farber GL, Place HM, Mazur RA, Jones DE, Damiano TR. Accuracy of pedicle screw placement in lumbar fusions by plain radiographs and computed tomography. Spine (Phila Pa 1976) 1995;20:1494-9.

8. Liljenqvist UR, Halm HF, Link TM. Pedicle screw instrumentation of the thoracic spine in idiopathic scoliosis. Spine (Phila Pa 1976) 1997;22:2239-45. 
9. Berlemann U, Heini P, Müller U, Stoupis C, Schwarzenbach $\mathrm{O}$. Reliability of pedicle screw assessment utilizing plain radiographs versus CT reconstruction. Eur Spine J 1997;6:406-10.

10. Schwarzenbach O, Berlemann U, Jost B, et al. Accuracy of computer-assisted pedicle screw placement: an in vivo computed tomography analysis. Spine (Phila Pa 1976) 1997;22:452-8

11. Calancie B, Lebwohl N, Madsen P, Klose KJ. Intraoperative evoked EMG monitoring in an animal model: a new technique for evaluating pedicle screw placement. Spine (Phila Pa 1976) 1992;17:1229-35.

12. Danesh-Clough T, Taylor P, Hodgson B, Walton M. The use of evoked EMG in detecting misplaced thoracolumbar pedicle screws. Spine (Phila Pa 1976) 2001;26:1313-6.

13. Lewis SJ, Lenke LG, Raynor B, Long J, Bridwell KH, Padberg A. Triggered electromyographic threshold for accuracy of thoracic pedicle screw placement in a porcine model. Spine (Phila Pa 1976) 2001;26:2485-9.

14. Raynor BL, Lenke LG, Kim Y, et al. Can triggered elec- tromyograph thresholds predict safe thoracic pedicle screw placement? Spine (Phila Pa 1976) 2002;27:2030-5.

15. Darden BV 2nd, Owen JH, Hatley MK, Kostuik J, Tooke SM. A comparison of impedance and electromyogram measurements in detecting the presence of pedicle wall breakthrough. Spine (Phila Pa 1976) 1998;23:256-62.

16. Calancie B, Madsen P, Lebwohl N. Stimulus-evoked EMG monitoring during transpedicular lumbosacral spine instrumentation: initial clinical results. Spine (Phila Pa 1976) 1994;19:2780-6.

17. Clements DH, Morledge DE, Martin WH, Betz RR. Evoked and spontaneous electromyography to evaluate lumbosacral pedicle screw placement. Spine (Phila $\mathrm{Pa}$ 1976) 1996;21:600-4.

18. Glassman SD, Dimar JR, Puno RM, Johnson JR, Shields $\mathrm{CB}$, Linden RD. A prospective analysis of intraoperative electromyographic monitoring of pedicle screw placement with computed tomographic scan confirmation. Spine (Phila Pa 1976) 1995;20:1375-9. 